\title{
Editorial Los Primeros 100 Días
}

L a métrica del desempeño en los primeros 100 días de un gobierno es una práctica que se ha establecido en diferentes industrias y presidencias en nuestro país y el extranjero. Ciertamente, el Comité Científico no está ajeno a esta tendencia, por lo que aprovecho esta oportunidad de comunicarlos, a la vez de hacer nuestro debut en sociedad.

En noviembre de 2016 se me ofreció la presidencia del Comité Científico de la Sociedad Chilena de Anestesia, la que acepté gustoso. El Directorio de la Sociedad ratificó al nuevo Comité Científico, que empezó a funcionar oficialmente en marzo de 2017. La primera gran tarea fue conformar el equipo de trabajo, que a partir de esta administración debían ser 13 integrantes, ojalá con presencia de mujeres, cosa que hasta la fecha había sido territorio exclusivo del sexo opuesto. Fue así que se conformó un directorio mixto, con representatividad de gran parte de las universidades del país que participan activamente en la formación de especialistas (Tabla 1) y con un entusiasmo de los integrantes que es digno de ser elogiado.

Hasta ese momento, no contábamos con un reglamento explícito que incluyera la visión, misión y objetivos del Comité. Fue así que trabajamos en la redacción y publicación de éste, luego de largas horas de meditación y varias versiones del manuscrito original. Finalmente, puedo decir con orgullo que ya contamos con una línea editorial para esta administración y las venideras" ${ }^{1}$.

La siguiente prioridad fue rescatar nuestra querida Revista Chilena de Anestesia nombrando al Dr. Dagoberto Ojeda como su timonel y dejando dicha publicación bajo la supervisión de este Comité. Se han invertido numerosas horas de planificación, recopilación de material pendiente y esfuerzo personal del Editor en Jefe para lograr contar nuevamente con la revista. Nuestro objetivo primario es que la revista logre un sitial importante en la literatura científica de habla hispana, sea un referente científico y que se constituya el método de difusión de este Comité y de la Sociedad de Anestesia en su totalidad. Los pasos iniciales que estamos dando son los de lograr su indexación, anhelo que ha sido perseguido desde ya varios años ${ }^{2}$ y que ahora queremos definitivamente consolidar. Si somos capaces de derribar las creencias limitantes, podremos lograr la tan anhelada indexación en Pubmed y transformarnos en una publicación con estándar International Scientific Indexing (ISI). Me parece que plantearse una tarea de esta envergadura a modo de visión es muy ambicioso, pero también

\begin{tabular}{ll}
\multicolumn{1}{c}{ Tabla 1. Integrantes del Comité Científico de la Sociedad Chilena de Anestesia 2017-2020 } \\
(ordenados por orden alfabético)
\end{tabular}


es una oportunidad que no debemos dejar escapar. Estoy esperanzado que este golpe de timón nos lleve a buen puerto.

Uno de los pilares fundacionales de este Comité es la investigación científica. Esta actividad ha sido y seguirá siendo de la mayor importancia, por lo que se redoblarán los esfuerzos para que más Socios de la Sociedad Chilena de Anestesiología puedan acceder a fondos de apoyo para la investigación, como también que puedan participar en el concurso de temas libres del Congreso Chileno de Anestesia. Hago hincapié en que quienes pueden acceder a dichos premios deben ser socios de la Sociedad, como un incentivo a pertenecer a ella y que de una vez por todas nos convenzamos que esta Sociedad es inclusiva y que quiere apoyar a sus socios en todas las áreas relevantes, particularmente en el ámbito científico. Los invito a participar activamente y a aprovechar dicho Comité para resolver dudas de sus investigaciones en curso o aquellas que estén en etapa de desarrollo y diseño. Es precisamente este el momento más valioso para recibir ayuda experta, de la que estamos muy dispuestos a entregar, con un equipo ávido de sus consultas.

Este Comité es la voz científica de la Sociedad Chilena de Anestesia y como tal, será quien organice las reuniones Científicas bimensuales de la Sociedad. A su vez, cooperará con el presidente del Congreso anual y el Directorio de la Sociedad en la preparación del programa científico, de manera que exista una continuidad año a año.

Finalmente y siguiendo con las tendencias digi- tales actuales, nuestro Comité ya tiene un sitio web exclusivo ${ }^{3}$, el que espero permita más acercamiento y sentido de pertenencia a sus usuarios.

A pesar de estar viviendo épocas de turbulencias políticas y sociales en nuestro país y el mundo, me siento esperanzado y muy optimista que este Comité al menos, va a funcionar bien y de acuerdo a las expectativas. Espero que el trabajo de estos primeros 100 días y de los que están por venir den sus frutos.

Héctor J. Lacassie

Presidente Comité Científico Sociedad Chilena de Anestesia

División de Anestesiología Pontificia Universidad Católica de Chile Marcoleta $377,4^{\circ}$ piso, Santiago e-mail: lacassie@med.puc.cl

\section{Referencias}

1. Comité_Científico, Visión y misión. (última actualización: editors. https://www.sachile.cl/comites/comitecientifico/mision-vision 15 de mayo (fecha de acceso).

2. Ricardo Bustamante, B, Roberto Canessa, B. Revista digital. Revista Chilena de Anestesia 2015; 44: 8-10.

3. Comité_Científico, Comité científico sachile. (última actualización: editors. https://www.sachile.cl/comites/ comite-cientifico/ 15 de mayo (fecha de acceso). 